\title{
Historiese Kritiek en die Ou Testament
}

\author{
H. F. VAN ROOY \\ Dept. Semitiese Tale, P.U. vir C.H.O.
}

\begin{abstract}
The issue surrounding the value of the various historico-critical methods of exegesis is dealt with in this article. The various methods (Form criticism, Literary criticism, History of transmission, Redaction history and Tradition history) are explicated and discussed. Literary criticism deals with the written sources used for the compilation of a work. Form criticism is concerned with the form in which statements have been poured. History of transmission (Überleferungsgeschichte) looks at the transmission of a certain section, also within the context of the period in which it was written down. Tradition history looks at the development and the run of specific traditions, such as the exodus from Egypt. Redaction history is concerned with the redaction or editing of a work, until it assumes its final shape.
\end{abstract}

In Ezekiel 29: 1-16 there is mention of a source, viz. the recording of the judgments of the prophet. The original judgement was in the well-known Qinaha metre, which was used especially for laments. Redaction history is of special interest here, because various forms of editing may be distinguished, through which the original prophetic judgment may be placed in a framework which changes the original prophetic judgment from judgment of the Jews to a judgment over Egypt. The investigation thus points to the fact that these methods may be fruitfully applied when adapted to a more conservative view of the Scriptures.

In die beoefening van die Ou-Testamentiese wetenskap in Suid-Afrika is daar 'n sterk tendens om baie ernstig aandag te gee aan die teks in sy huidige vorm, ook in die eksegese. Daar word dan van teksimmanente eksegese gepraat (Deist 1973, p. 77), waarin die huidige vorm van die teks die ondersoekgebied is. Dit is 'n tendens wat sekerlik verwelkom moet word, ook omdat dit iets van 'n teenvoeter bied vir die versnippering wat gewoonlik uit die histories-kritiese metodes gevolg het. Hierdie teksimmanente benadering leun baie sterk op die Algemene Taal- en Literatuurwetenskap. Hierin word die Ou Testament as 'n stuk literatuur benader, met die gepaardgaande gevaar dat die uniekheid van die Bybel daardeur in gedrang kan kom. Dit beteken egter nie dat die sogenaamde histories-kritiese benadering daarmee vaarwel toegeroep is nie. Dit speel nog ' $n$ baie groot rol in die benadering van die Ou Testament van heelwat, veral jongere, Ou-Testamentici in Suid-Afrika. 


\section{H. F. van Rooy}

Alhoewel die konserwatiewer Ou-Testamentici wel soms sal toegee dat daar sekere ptobleme is wat deur die historiese kritiek raakgesien en gehanteer word, is die meeste van hulle tog sterk afwysend daarteenoor. So sê Verhoef (1973, p. 48) oor die literêre kritiek dat hy nie oor die orgaan beskik om al die gewerskaf te waardeer nie. Hierdie kritiek teen die historiese metodes hang baie nou saam met die voorveronderstellings van hierdie metodes. Hierdie voorveronderstellings sluit die opvatting oor inspirasie in. Dit is opmerklik dat die historiese metodes hulle ontstaan en ontwikkeling meesal in Lutherse kringe gehad het. Deist (1973, p. 78-80) onderskei effens simplisties maar tog funksioneel tussen die Lutherse en Calvinistiese Skrifbeskouings en -opvattings oor die inspirasie. Die Calviniste beskou die Bybel soos wat dit is, as die Woord van God, terwyl die Lutherane sê dat die Woord van God in die Bybel is - dit moet dus daaruit gefiltreer word. Die Calviniste maak inspirasie van toepassing op die oorspronklike openbaring en op die hele proses wat gelei het tot die finale vorm wat die Bybel het. Daarenteen maak die Lutherane die inspirasie net op die oorspronklike openbaring van toepassing. Omdat hulle besonderlik daarin belangstel, is die historiese metodes ontwikkel om daardeur tot 'n rekonstruksie van die oorspronklike openbaring te kom. Die historiese kritiek sien die taak van eksegese as die rekonstruksie van daardie oorspronklike openbaring, terwyl eksegese in die Calvinistiese standpunt die tak het om die teks in sy finale vorm te verklaar.

'n Ander baie belangrike kritiek teen die historisme is dat die histories-kritiese metodes sonder 'n sogenaamde God-hipotese werk (Hasel 1972, p. 30). Die historiese metodes soek na die krities bevestigde minimum (Von Rad 1975a, p. 108). Hierin word geskiedenis gesien as 'n afgeslote geheel, 'n reeks bestaande uit oorsake en gevolge waarin daar geen plek vir die transendente is nie (Hasel 1972, p. 84, 85; Von Rad 1975b, p. 418). Dit is miskien hieraan te wyte dat die historiese metodes onder die noemer "hoër kritiek" saamgevat is. Die Bybel word vanuit 'n kritiese hoek benader, sodat daar ook teen die inhoud van die Bybel kritiek uitgespreek word. Hierdie metodes moet inderdaad beoordeel word teen die agtergrond van die filosofie wat gangbaar was toe die metodes ontwerp is. So kan die invloed van die Rasionalisme duidelik aangetoon word wanneer daar vir 'n ingrype van God in die geskiedenis geen ruimte gelaat word nie. Ook Hegel se filosofie met sy skema van tese-antitese-sintese het duidelik 'n invloed gehad. Ten opsigte van die Ou Testament het dit onder andere uitgeloop op die gedagte dat daar 'n ontwikkeling in die godsdiens van Israel moes gewees het van 'n meer primitiewe godsdiens tot by die monoteisme. Op grond hiervan is die verbondsgedagte as een van die jonger ontwikkelings 
in die godsdiens van Israel beskou. Dat daar 'n verbond van God met Abraham Daarom moes hierdie gedagtes 'n terugprojeksie van latere gebeure in die vroeë geskiedenis van Israel gewees het.

Dit is dus ongetwyfeld so dat die ontstaan van hierdie metodes en die ontplooiing daarvan teen 'n bepaalde agtergrond geplaas moet word en dat daar baie sterk beswaar daarteen aangeteken kan word deur teoloë wat aan die Bybel as die Woord van God vashou. Tog is dit ook waar dat hierdie metodes sekere wettige sake raakgesien het waarmee inderdaad rekening gehou moet word. Dit behoort uit 'n kort uiteensetting van die verskillende historiese metodes duidelik te blyk.

\section{DIE LITERêRE KRITIEK}

Die logiese beginpunt is die literêre kritiek, wat veral by Julius Wellhausen sy beslag gekry het. Sedert Wellhausen was daar ook baie ontwikkelinge op hierdie gebied, sodat dit vandag nie meer baat om teen Wellhausen te velde te trek nie. Tog bied sy sieninge 'n goeie beginpunt, omdat van die latere eksponente so in besonderhede opgegaan het dat die Ou-Testamentiese dokumente heeltemal versplinter geraak het. Ten opsigte van die eerste vyf boeke van die Ou Testament (Genesis tot Deuteronomium) het hy vier bronne onderskei. Dit is die tipiese van die literêre kritiek dat dit agter die huidige gestalte van 'n Ou-Testamentiese geskrif bronne soek. Hierdie bronne van die eerste vyf boeke word gewoonlik aangedui as J, E, D en P. J is die Jahwistiese bron, E die Elohistiese, $\mathrm{D}$ die Deuteronomiese en $\mathrm{P}$ die Priesterkodeks. Die onderskeid tussen die eerste twee bronne hang in 'n mate saam met die gebruik van die Godsname Yahwe en Elohim. Die Deuteronomiese hou verband met Deuteronomium, en die Priesterkodeks omvat die voorskrifte in verband met die tabernakel, die priesterdiens en verwante sake. Die J-bron is die oudste, en daarna volg E. Hulle word beide voor die ballingskap gedateer en so ook die derde bron, D. $\mathrm{D}$ word verbind met die wetboek wat in die tyd van koning Josia in die tempel gevind is, dit wil sê in die tweede helfte van die sewende eeu v.C. P dateer egter uit die tyd na die ballingskap, teen die vyfde eeu v.C. Daarin het die Ou-Testamentiese godsdiens die hoogtepunt van sy ontwikkeling bereik.

Alhoewel daar wettige kritiek teen hierdie soort evolusionistiese benadering ingebring kan word, is die opvatting betreffende bronne nie te kritiseer nie. Wie aan 'n organiese inspirasie vashou, kan nie by die skrywer van 'n boek verbykyk nie. Selfs al het Moses die eerste vyf boeke geskryf, moes hy tog sy 


\section{H. F. van Rooy}

gegewens oor bv. Abraham van vyf, ses eeue voor hom êrens vandaan gekry het, om nie eers van die gegewens oor die skepping en vroeë figure soos Noag te praat nie. Hy sou dus van bronne gebruik moes maak, en om daarna te vra is sekerlik 'n wettige vraag wat op die terrein van die Besondere Kanoniek lê.

\section{VORMKRITIEK}

Die metode wat histories besien na die literêre kritiek ontwikkel het, is die vormkritiek (Formgeschichte). Hier was Hermann Gunkel die baanbreker. Hy wou selfs by die bronne verbybeweeg na die oorspronklike gedeeltes wat van die bronne ten grondslag gelê het. Veral het hy gelet op die literêre vorme (genre, Gattung) waarin daardie oorspronklike gedeeltes gegiet is. In daardie oorspronklike gedeeltes was daar baie konsekwentheid ten opsigte van die verskillende vorme. So was daar spoedig vaste vorme vir 'n triomflied na 'n oorwinning, vir klaagliedere, vir koningsliedere, vir historiese verhale en so meer (Van Zyl 1972, p. 152). So was daar 'n verband tussen die literêre vorm en die ontstaansplek daarvan in die lewe van die volk. Dit word gewoonlik die Sitz im Leben genoem. Wie dus 'n sekere vorm kan herken, weet al baie oor die ontstaansituasie van die betrokke gedeelte. Deur hierdie metode kan ook onderskei word wat tipies Israelities is en wat nie (Deist 1976, p. 72). Alhoewel oor hierdie metode positiewer geoordeel word (Verhoef 1973, p. 51), is dit tog nie sonder gevare nie. Hierdeur kan die Bybel nog verder versnipper word, sodat 'n boek as 'n versameling los vorme gesien word en nie as 'n eenheid nie. Tog kan die belang van vorme nie ontken word nie, en dit kan inderdaad belangrike lig op gedeeltes van die Bybel, selfs hele boeke, werp wat vir die Eksegese baie vrugbaar kan wees.

\section{OORLEWINGS- EN TRADISIEGESKIEDENIS}

Twee verskillende metodes wat dikwels nie goed onderskei word nie, is die oorleweringsgeskiedenis (Überlieferungsgeschichte) en tradisiegeskiedenis (Traditionsgeschichte). Oorleweringsgeskiedenis wil verder teruggaan as die vormkritieke, en daarin word gewoonlik baie klem op die mondelinge oorlewering gelê. Baie gedeeltes van die Ou Testament (soos bv. die profetiese uitsprake) is mondeling gelewer en deur mondelinge oorlewering bewaar totdat dit op die ou end op skrif gestel is. Die oorleweringsgeskiedenis wil hierdie mondelinge oorleweringsfase van 'n verhaal of uitspraak ondersoek. Tradisiegeskiedenis kyk weer na die geskiedenis van 'n sekere tradisie, 'n sekere gedagte, deur die hele omvang 


\section{Historiese Kritiek en die Ou Testament}

van die literatuur, skriftelik en mondeling (Deist 1976, p. 144 n., 81). So 'n tradisie is byvoorbeeld die eksodusmotief of die verbondsluiting by Sinai. Hierdie gedagte word dan oor die hele spektrum van die Ou Testament ondersoek. Dit is die metode wat baie sterk by Von Rad leef. Veral die oorleweringsgeskiedenis is baie hipoteties en daarom vir misbruik vatbaar. Wie aan die gesag van die Woord in sy huidige vorm vashou, het inderdaad nie veel begeerte om hom hierin te begewe nie, en tog kan dit in sekere gevalle met groot nut gebruik word.

\section{REDAKSIEGESKIEDENIS}

In die bogenoemde metodes is die groot leemte dat die eenheid van die Bybelbocke heeltemal uit die oog verloor word. Daar word gekonsentreer op bronne, op literêre vorme, op die mondelinge en skriftelike oorlewering van kleiner eenhede en op die ontwikkeling en samehang van tradisies. Hierop is die redaksiegeskiedenis in 'n sekere mate 'n korrektief. Dit wil let op die verwerking van die st of tot 'n boek en die finale "uitgewer" van die boek. Die bydrae van die verwerkers, die skrywers eerder, kom so meer tot hulle reg. Die skrywers van die historiese bocke het nie maar alle feite wat hulle geken het, weergegee nie. Steeds wou hulle vanuit 'n sekere hoek die geskiedenis benader, en dit het ongetwyfeld in hulle keuse van die stof 'n rol gespeel. So moct ook die eie bydrae van elke skrywer raakgesien word.

Alhocwel die wyse waarop hierdie metodes deur die kritiese teoloë gebruik is, om prinsipiële redes nie nagevolg kan word nie, is dit waar dat hulle sekere wettige terreine van ondersoek aangedui het. Dit mag nie verabsoluteer word, asof hierdie metodes objektiewe, wetenskaplike eksegese waarborg nie. So iets is daar nie. Skrifbeskouing speel 'n geweldige rol in sowel die keuse as die hantering van metodes en bepaal so ook die resultate. Tog kan die ondersockterreine wat die historiese metodes blootgelê het, met vrug ten dienste van dic eksegese gebruik word.

\section{TOEP̄ASSING VAN DIE METODES OP ESEGIEL 29:1-16}

Om dit prakties te illustreer word Esegiël 29:1-16 aan die hand van die metodes benader. Wanneer die metodes toegepas word, word dit wel gedoen met 'n hecl ander uitgangspunt as die wat vir die kritiese teoloc̈ geld. Die gesaghebbende karakter van die Bybel as die geopenbaarde Woord van ciod word ten volle gecerbiedig, en die werk van God in die geskiedenis word ten volle crken. Ilicrdic 


\section{H. F. van Rooy}

uitgangspunt moet by die toepassing van hierdie metodes sy invloed laat geld Ten opsigte van Esegiël self en die totstandkoming van sy boek is daar ook baie standpunte, en dit is nie moontlik om hier volledig op alles wat daarmee verband hou, in te gaan nie. Daarvoor kan die werke van Taylor $(1969$, p. 13-51), Harrison (1970, p. 822-55) en uit 'n effens ander hoek Cooke (1970, p. xv i i$x$ iv $i$ i) geraadpleeg word.

Dit is wel duidelik dat die boek 'n sekere geskiedenis moes deurgemaak het voordat dit sy huidige vorm bereik het. Daar het volgens die datums wat in die boek self gegee word, 'n periode van ongeveer 22 jaar verloop tussen die jongste. en oudste profetiese uitsprake in die boek. Hoe die datums presies geinterpreteer moet word, is wel iets van 'n problematiese saak. Smit (1965) het die datums rakende die val van Jerusalem goed bespreek en plaas die val van Jerusalem in 586 v.C. Taylor (1969) plaas dit weer in 587 v.C. In elk geval het Esegiël se profetiese werksaamheid het ses jaar voor die val van Jerusalem begin en aangehou tot sestien jaar daarna, dus 'n tydperk van twee en twintig jaar. It is logies dat die boek sy huidige vorm aangeneem het nadat die profeet sy laaste uitspraak gelewer het. Indien 'n mens sou aanvaar dat die profeet self vir die boek in sy huidige vorm verantwoordelik is, moes daar in elk geval nog steeds ' $n$ periode van meer as twee en twintig jaar verloop het vanaf sy eerste optrede totdat die boek saamgestel is. ' $n$ Ander moontlikheid is dat een van sy leerlinge die boek saamgestel het. Die periode kon dan 'n bietjie langer gewees het, maar daar is geen dringende noodsaaklikheid om die samestelling van die boek aan die begin van die volgende eeu te dateer, soos May (1956, p. 43) doen nie. In dịe periode van meer as twintig jaar kon die oorspronklike stof inderdaad aangepas of uitgebrei gewees het om by veranderde omstandighede aan te pas of om die betekenis duideliker na vore te bring. Dit is ook duidelik dat die inhoud van die boek logies en in ' $n$ hoë mate chronologies gerangskik is. Hierdie proses waardeur die stof gegaan het, open die moontlikheid dat die historiese metodes belangrike resultate kan lewer. Die gesaghebbendheid van die stof bly natuurlik dwarsdeur die hele proses gehandhaaf.

\section{BRONNE}

Die literêre kritiek stel belang in moontlike bronne wat aan die boek ten grondslag lê. Hier sou as bron kon geld die opgetekende uitsprake van Esegiël opgeteken deur homself of deur iemand wat nou a an hom verbonde was. Hierdie uitsprake kon voorlopig versamel en met verloop van tyd aangevul gewees het deur latere uitsprake, en hierdie versameling het dan as grondslag gedien vir die 


\section{Historiese Kritiek en die Ou Testament}

finale samesteller van die boek - of dit nou Esegiël self was of iemand wat aan hom verbonde was. Wat presies in die bron gestaan het, kan moeilik bepaal word, alhoewel dit ten opsigte van Esegiël 29 noukeuriger bepaal kan word, soos die verdere argumentasie sal aandui.

Die vormkritiek soek na die oorspronklike vorme, in die geval van Esegiël 29:1-16 die vorm van die oorspronklike profetiese uitspraak van Esegiël gerig aan die ballinge op die twaalfde dag van die tiende maand van die tiende jaar van die ballingskap van Jojagin. Hier moet die teks self die aanduiding gee. So is dit duidelik dat in vers 1 tot aan die begin van vers 3 'n inleidingsformule gegee word waarin die uitspraak gedateer word en die opdrag van die Here aan Esegiël gegee word. Die res van die gedeelte kan in sy huidige vorm in drie dele verdeel word (3-7; 8-12 en 13-16), wat aldrie met 'n vaste refrein - "so sê die Here Jahwe" - begin. Daar kan aanvaar word dat die vaste refrein met die finale verwerking deel van die geheel geword het. Alhoewel die geheel van vers 3 tot 16 as 'n gedig met drie strofes beskou kan word (Van Rooy 1981) is dit duidelik dat die strofe 3:7 'n taamlik konsekwente metrum vertoon, terwyl die ander twee strofes dit nie vertoon nie. Vir die vormkritiek is dit 'n belangrike aanduiding ten opsigte van die oorspronklike gedeelte. Verder word daar in die eerste strofe (3-7) twee uitdrukkings aangetref wat telkens elders in die boek voorkom. Dit is die uitspraak " $\mathrm{Kyk}$, Ek het dit teen jou . . . " in vers 3 en "sodat al die inwoners van Egipte sal weet dat Ek Jahwe is". May (1956, p. 50,51) onderskei meer as vyftig uitdrukkings wat telkens in die boek voorkom en wat sowel deur verspreiding as gebruik waarskynlik deel uitmaak van die stof wat met die finale samestelling deel van die boek geword het. Gevolglik kan die twee uitsprake en ook die res van vers 6 en vers 7, wat by die uitspraak aan die begin van 6 aansluit, nie deel van die oorspronklike uitspraak wees nie. Die metrum van die gedeelte is nie heeltemal konsekwent nie. Aan die begin vertoon die gedig 'n taamlik vaste patroon, maar algaande word daarvan afgewy bestaan normaalweg uit twee en soms uit drie bene, en om die metrum te bepaal word normaalweg slegs die aantal beklemtoonde lettergrepe in elke been bepaal. 'n Vers met 'n 4:4-metrum bestaan dus uit twee bene wat elk vier beklemtoonde lettgrgrepe het. Benewens 'n 4:4-metrum is ander gewilde patrone 2:2, 3:2, 3:3 en 4:3. Dikwels kom daar in 'n gedig nie 'n vaste skema voor nie, alhoewel daar gewoonlik ' $n$ oorheersende een is. Die 3:2-metrum word dikwels in klaagliedere gebruik, soos byvoorbeeld in 'n groot deel van die boek Klaagliedere. Hierdie

1. Dit word voorgestel in 'n artikel wat in die 1981-uitgawe van die tydskrif Semitics gepubliseer sal word. 


\section{H. F. van Rooy}

3:2-metrum kom duidelik na vore in veral die eerste deel van hierdie gedig, en dit is inderdaad moontlik om 'n (hipotetiese) oorspronklike uitspraak te rekonstrueer wat as geheel hierdie metriese patroon vertoon. Dit sien in die Hebreeuse konsonantteks soos volg daaruit:

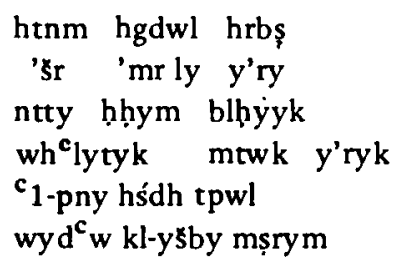

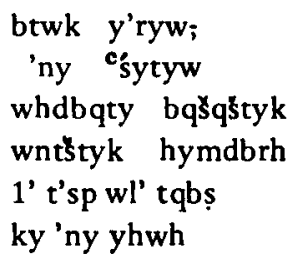

Dit is 'n kort klaaglied bestaande uit ses verse met 'n konsekwente metriese patroon. In Afrikaans vertaal, is die klaaglied soos volg:

Die groot draak wat lê te midde van sy Nylstrome wat sê: My Nyl is myne, ekself het dit gemaak Ek sal hake in jou kake gee en Ek sal dit aan jou skubbe laat kleef. Ek sal jou uit jou Nylstrome laat uitkom en jou in die woestyn wegwerp. Op die veld sal jy val. Jy sal nie bymekaargemaak of versamel word nie Daarna sal al die inwoners van Egipte weet dat Ek Jahwe is.

Dit is dus ' $n$ aankondiging van oordeel wat in die vorm van 'n klaaglied gegiet is. Wat natuurlik in gedagte gehou moet word, is dat hierdie uitspraak nie tot die Egiptenare of die Egiptiese farao gerig was nie maar tot die ballinge in Babilonië. Hierdie ballinge was mense wat deur Nebukadnesar saam met Jojagin uit Jerusalem weggevoer is. Met daardie eerste inname van Jerusalem deur Nebukadnesar is die stad self egter nie verwoes nie (II Kon. 24:8-17 - kyk ook Smit 1965, p. 33-7). Esegiël was self een van die ballinge wat toe weggevoer is. Die vernaamste begeerte van daardie ballinge was sekerlik om na hulle land terug te keer. In Jerusalem is Sedekia, Jojagin se oom, as koning aangestel. In Sedekia se negende jaar het hy blykbaar met die farao van Egipte saamgesweer en teen Nebukadneser gerebelleer. In die tiende jaar van Sedekia het die farao na Jerusalem opgetrek om Sedekia te hulp te kom, en as gevolg daarvan is die beleg selfs tydelik opgehef. Dit was egter maar net tydelik, en daarna is die beleg voortgesit totdat die stad ingeneem en verwoes is. In die opstand teen Nebukadnesar is daar dus op Egipte vertrou. Volgens die datering van hierdie uitspraak van Esegiël is die woorde oor Egipte uitgespreek nadat die beleg 


\section{Historiese kritiek en die Ou Testament}

van Jerusalem begin het maar voordat die stad ingeneem en verwoes is (Smit 1965, p. 92-3). Die ballinge het sekerlik in die hoop op Egipte gedeel. Terwyl hulle dus op Egipte hoop om uit die ballingskap verlos te word, kom sing Esegiël 'n klaaglied oor Egipte. Die implikasies hiervan moes vir die oorspronklike hoorders so duidelik gewees het dat dit nie vir Esegiël nodig was om te sê waarom hy die klaaglied sing en wat die beeldspraak alles beteken nie. Die ballinge hoop op Egipte - en Esegiël sing 'n klaaglied oor Egipte. De ur gebruikmaking van hierdie vorm is die valse hoop van die ballinge duidelik aangetoon.

In hierdie gedeelte sal oorleweringsgeskiedenis nie veel resultate lewer nie, aangesien redelikerwys aanvaar kan word dat hierdie uitspraak spoedig opgeteken is. Die tradisiegeskiedenis is van meer belang, omdat die saak van valse vertroue op Egipte van die kant van Juda meermale voorgekom het. So was dit ook in die tyd van Hiskia, soos in Jesaja 36 gesien kan word. Vertroue op heidense nasies is meermale baie streng bestraf. Ook Sedekia, wat in Jerusalem op die troon was toe Esegiël in Babilonië opgetree het, het op Egiptiese hulp teen Nebukanesar gehoop. Jeremia, 'n ouer tydgenoot van Esegiël, het in Jerusalem geprofeteer dat hierdie hulp van geen nut sal wees nie (Jeremia 37:7,8).

Die redaksiegeskiedenis van hierdie gedeelte bied ook belangrike gegewens. Dit is duidelik dat die oorspronklike kort orakel algaande uitgebrei is om op die ou end sy huidige vorm en plek in die boek van Esegiël te kry. In die redaksionele verwerking kan daar vier stadiums onderskei word, wat nie noodwendig op verskillende tye geplaas moet word nie. (Hier sal dit gerieflik wees om die oorspronklike orakel soos bo gegee voortdurend met 'n vertaling van die gedeeltes te vergelyk.)

Eerstens is die oorspronklike orakel self deur sekere byvoegings aangevul, veral in vers 4 en 5 . Daardeur word die oordeel uitgebrei na die hofdienare en volgelinge van Farao, die vissies wat aan sy skubbe kleef en wat saam met die groot krokodil in die woestyn weggewerp sal word.

Tweedens is daar deur nog 'n metafoor (in vers 6 en 7) 'n verduideliking gegee waarom die klaaglied oor Farao gesing is. Vir die oorspronklike hoorders was dit duidelik sonder die byvoeging dat Egipte vir Israel 'n rietstok is, dit wil sê 'n swak bron van hulp. Tradisie-histories kan hierdie byvoeging verbind word aan die uitspraak van die Assiriese offisier in Jesaja 37, waar Egipte 'n geknakte rietstok genoem word. 


\section{H. F. van Rooy}

Derdens is die gedeeltes van vers 8-12 en 13-16 bygevoeg om die twee metafore oor die groot krokodil en die rietstok te verduidelik. Hierdeur word eksplisiet gesê wat implisiet deur die metafore uitgebeeld is.

Vierdens kom die finale vasstelling van die gedeelte. Daarmee hang saam die datering van die uitspraak en die redaksionele gedeeltes in vers 1-3, 6, 8, 9, 13 en aan die einde van vers 16 . Onmiddellik daarna word dan 'n ander uitspraak van Esegiel geplaas (vers 17-21) waarin uitgespel word dat hierdie oordeel oor Egipte de ur Nebukadnesar voltrek sou word.

Veral belangrik in die finale verwerking van die gedeelte is die uitspraak in vers 6, 9 en 16 dat die hele Egipte sal weet dat God die HERE is. In die finale gedig word hierdie drie frases besonder beklemtoon, en hulle vorm eintlik die kernpunt van die hele gedeelte. Daardeur kom daar egter iets van 'n verandering in die betekenis van die hele gedeelte. Aanvanklik is die oorspronklike uitspraak gemaak om die valse hoop van die ballinge in Babilonië uit te wys. Met die finale samestelling van die boek was dit nie meer nodig nie, want Jerusalem is klaar vernietig, en dit was vir almal duidelik dat die verwagting van die ballinge om na Jerusalem terug te keer - voor die verwoesting - vals was. $\mathrm{Na}$ die vernietiging van Jerusalem het Esegiël nie meer die oordeel verkondig nie - soos in die eerste vier en twintig hoofstukke van sy boek opgeteken - maar ' $n$ boodskap van hoop gebring. Dit word gedra deur die oortuiging dat die Here Koning van die hele wêreld is. In die finale vorm van dic gedig in Esegiël 29:1-16 spreek hierdie oortuiging duidelik. Tot selfs Egipte sou dit moes erken. Ook Egipte kom onder die oordeel, juis omdat Egipte vir Israel 'n bron van valse vertroue was.

Uit hierdie bespreking is dit duidelik dat die sogenaamde historiese metodes tog met vrug gebruik kan word om agtergrond te verskaf waarteen 'n gedeelte beter bestudeer kan word om so die boodskap daarvan duidelik te laat spreek, ook vir vandag.

\section{BIBLIOGRAFIE}

COOKE, G.A. 1970.

DEIST, F.E. 1973.

The Book of Ezekiel. Edenburgh: T. \& T. Clark. Ou Testamentiese eksegese en Algemene Literatuurwetenskap. (In Nederduits Gereformeerde Teologiese Tydskrif 14 (1): 75-81). - 1976.

Mosaiek van Moses. Kaapstad: Tafelberg.

HARRISON, R. K. 1970. Introduction to the Old Testament. London: Tyndale. HASEL, G. 1972

Old Testament Theology: Basic issues in the current debate. Grand Rapids: Eerdmans. 
Historiese kritiek en die Ou Testament

MAY, H.G. 1956.

SMIT, E. J. 1965.

TAYLOR, J. B. 1969. VAN ROOY, H. F. 1981.

VAN ZYL, A. H. 1972.

VERHOEF, P. A.

VON RAD, G. 1975 a.
Ezekiel. (In The Interpreter's Bible 6. New York: Abingdon). Die ondergang van die ryk van Juda. Proefskrif, VU, Amsterdam.

Ezekiel. London: Tyndale.

Parallelism, metre and rhetoric in Ezekiel 29:1-16.

Voordrag, Semitics-kongres, 1980 (Publikasie in

Semitics 1981 afgewag.)

Literere vorme en Eksegese. Nederduits-Gere-

formeerde teologiese tydskrif ${ }_{n} 13(3)$ : 149-59.

Metodiek van die Eksegese. Kaapstad: NG Kerkuitgewers.

Old Testamenc Theology 1. London: SCM.

Old Testament Theology 2. London: SCM 